\title{
AGRICULTURA URBANA NOS VAZIOS URBANOS DE GOIÂNIA: Estratégia de adaptação das cidades às mudanças climáticas globais
}

\author{
Urban agriculture in the urban voids of Goiânia: \\ Strategy for adapting cities to global climate change
}

\author{
A. Luiza Amaral Daher \& B. Karla Emmanuela Ribeiro Hora \\ Universidade Federal de Goiás, Brasil \\ luizadaher@gmail.com \\ Karlaemmanuela@gmail.com
}

\begin{abstract}
RESUMO
Este artigo tem como temática o estudo da agricultura urbana como estratégia de adaptação das cidades no contexto das mudanças climáticas globais aplicado aos vazios urbanos em Goiânia. As mudanças climáticas, entendidas pela desregulação dos padrões meteorológicos, dadas pelos padrões de uso da terra e do solo, requerem medidas mitigadoras e adaptativas para tornar as cidades resilientes. Dentre as possibilidades de ações de adaptação esse estudo se ancora na prática de agricultura urbana. Nesse contexto, um dos aspectos primordiais é o da necessidade de áreas apropriadas para sua prática na cidade. Sendo assim, busca-se identificar se os vazios urbanos podem ser aproveitados para a atividade de agricultura urbana em Goiânia, considerando as reflexões sobre sustentabilidade ambiental, cumprimento da função social da propriedade urbana e direito à cidade. A pesquisa é de natureza aplicada e explicativa e se fundamenta em procedimento técnico de pesquisa bibliográfico e documental.
\end{abstract}

Palavras-chave: agricultura urbana, vazios urbanos, adaptação das cidades, Goiânia.

Linha de Investigação: Cidade e Ambiente.

Tópico: Meio ambiente, paisagem e alterações climáticas.

\section{ABSTRACT}

This article studies urban agriculture as a strategy for adapting cities in the context of climate change applied to urban voids in Goiânia. As climate changes, understood by the deregulation of meteorological patterns, given by the patterns of land use system, need to mitigating and adaptive measures to make cities resilient. Among the possibilities for adapting cities, this article is based in practice of urban agriculture. In this context, one of the primary aspects in the need for appropriate areas for their practice in the city. Therefore, it seeks to identify if the urban voids can be used for urban agriculture in Goiânia, considering reflections on environmental sustainability, according of the social function of urban property and guaranteeing the right to city. This research is of an applied and explanatory nature and is based on bibliographical and documentary research.

Keywords: urban agriculture, urban voids, adapting cities, Goiânia.

Research line: City and Environment.

Topic: Environment, landscape and climate change. 



\section{SÃO PAULO15 $\sim 17 \cdot$ LISBOA $25 \sim 26$ JUN 2020

De acordo com o mapeamento realizado por Sousa (2019), em Goiânia é possível identificar, pelo menos, 159 unidades territoriais com práticas de agricultura em sua área urbana e periurbana. Essa atividade tem o fator locacional como uma das condições de sua existência, sendo influenciados por três principais condicionantes: o preço da terra, disponibilidade de área livre (não edificada) e acesso à água. Essas práticas são ofertantes de postos de trabalho e geradoras de renda para seus praticantes. Entretanto há outras atividades de agricultura urbana cujo escopo fundamenta-se em preocupação ambiental, ocupacional ou educacional e tendem ser gestadas por organizações não governamentais.

Porém, uma questão a se considerar é se há possibilidade de destino dos vazios para a prática da agricultura urbana. O Plano Diretor de Goiânia prima pela ocupação dos vazios urbanos por meio do adensamento urbano, ou seja, elevação do gradiente construtivo por meio da oferta habitacional (Goiânia, 2007). Assim, a forma de combater os vazios urbanos seria disponibilizá-los como áreas para construção de novas edificações, o que não é o proposto da agricultura urbana, já que ela pretende trabalhar com produção de alimentos saudáveis vinculados a práticas de educação e/ou assistência social.

A partir da contextualização exposta, o artigo parte da seguinte questão: os vazios urbanos podem ser utilizados para a agricultura urbana como estratégia de adaptação das cidades às mudanças climáticas globais em Goiânia?

A contribuição da pesquisa encontra-se fundamentada nas discussões atuais sobre as estratégias de enfrentamento das cidades perante às mudanças climáticas globais. As cidades precisam estar preparadas diante da atual realidade de câmbio nos padrões meteorológicos em que as chuvas torrenciais se apresentam com maior frequência e os períodos de estiagem se prolongam.

Dessa forma, a prática de agricultura urbana aparece como uma das estratégias de adaptação das cidades a essas mudanças, uma vez que, possibilita um uso do solo de forma tal que se garanta a sua não impermeabilização, aliada a práticas de inclusão social e educação ambiental. Assim, tais práticas, além de promover reflexos positivos quanto a questões ambientais, também responde positivamente social e economicamente. No que tange a espacialização dessa prática os vazios urbanos se apresentam como áreas passíveis de ocupação. Esses vazios urbanos são áreas que descumprem a função social da propriedade urbana. Além de ser previsto em lei que esses espaços não devam permanecer ociosos, eles ainda trazem prejuízos para a cidade.

Para tanto, tornou-se pertinente a discussão da agricultura urbana no contexto das estratégias de adaptação das cidades às mudanças climáticas globais, discutir também o direito à cidade e a função social da propriedade urbana quando se pensa em vazios urbanos para, finalmente, incluir o caso de Goiânia no debate.

\section{Agricultura urbana no contexto de adaptação das cidades às mudanças climáticas globais}

Muito se tem discutido a respeito dos reflexos das mudanças climáticas nas cidades e como elas podem e devem se tornar resilientes (Giddens, 2010; Barbieri; Viana, 2013; Ojima, 2013). As cidades são comumente vistas como o cenário dos "impactos socioeconômicos e ambientais negativos e baixa condição de justiça ambiental" (Bueno, 2013, p. 50). Porém, segundo Ojima (2013, p. 253), são essas mesmas cidades que "vemos o desenvolvimento econômico, as mudanças sociais, a inovação tecnológica e, como a tendência de um mundo cada vez mais urbano é preciso extrair desse modo de vida todo o potencial produtivo e criativo para resolver os problemas que nelas emergem com mais força". 


\section{SÃO PAULO15 17 LISBOA $25 \sim 26$ JUN 2020

As mudanças climáticas globais podem ser entendidas pela desregulação dos padrões meteorológicos, sendo observadas nos seguintes aspectos: aumento médio da temperatura na superfície terrestre (aquecimento global); alteração no padrão das precipitações (ocasionando tempestades, enchentes e secas); aumento da poluição do ar, do solo e da água; e emissão de gases poluentes, principalmente o dióxido de carbono - o que ocasiona o efeito estufa (Leite, 2012). Essas alterações estão diretamente ligadas às mudanças nos padrões de uso da terra e do solo, principalmente, pós-revolução industrial. Elas estão diretamente relacionadas ao modo de produção e de consumo, pautada na desigualdade (Sposito, 2003; Bueno, 2013; Maricato, 2015.).

Dentre as mudanças, a alteração do ciclo hidrológico tem impacto significativo nos sistemas de drenagem urbana. Os sistemas de microdrenagem não conseguem vencer a ocorrência de eventos chuvosos extremos, levando a cidade a conviver com pontos de inundação e alagamentos. Além do aumento das chuvas torrenciais, o processo de urbanização com o excessivo parcelamento do solo e a impermeabilização das grandes superfícies dificulta a infiltração da água da chuva e acelera o escoamento superficial (Silva; Hora, 2013).

Face a esse cenário, os organismos internacionais têm buscado mediações entre os governos visando a construção de pactos e de uma agenda que possa mitigar os problemas climáticos decorrentes da ação da sociedade. A Nova Agenda Urbana (HABITAT III, 2016, p. 2), por exemplo, traz, no seu 8을 Documento de Políticas, questões fundamentais como ecologia e resiliência urbana. O documento discute que,

Devemos trabalhar em favor de um futuro urbano que seja ambientalmente sustentável, ecologicamente saudável, de baixo-carbono, eficiente no uso dos recursos, e com cidades resilientes que tenham a capacidade de mitigar e adaptarse a uma grande variedade de choques e estresses. [...] A incorporação das questões ambientais no processo de decisão é uma maneira para melhorar a qualidade de vida dos cidadãos e elevar a competitividade das cidades.

De acordo com a literatura existem práticas de mitigação e práticas de adaptação para o enfrentamento das cidades perante às mudanças climáticas globais. As práticas de mitigação se referem ao embate do fato gerador, ou seja, são ações que enfrentam diretamente o causador do problema, como por exemplo a diminuição das emissões de gases do efeito estufa. Essas estratégias têm certa dificuldade de implementação e seus resultados são sentidos a longo prazo e em nível global (Barbieri; Viana, 2013).

Já as práticas de adaptação "visam atenuar os impactos das mudanças climáticas e, por isso, alguns autores consideram que, diferentemente das medidas mitigadoras, seus impactos são sentidos de maneira mais imediata e seus benefícios são mais localizados" (Barbieri; Viana, 2013, p.60). Ou seja, as medidas adaptativas são pensadas numa escala menor inferindo ações precisas com retornos mais rápidos e mais palpáveis.

As iniciativas urbanas de adaptação das cidades às mudanças climáticas globais abordam diferentes aspectos, seja de mitigação de carbono, seja de eficiência energética, seja no rearranjo do ciclo de vida, seja de implementação de infraestruturas verdes. As cidades, além de se prepararem, precisam se adaptar a essa nova realidade imposta pelas mudanças climáticas globais e a prática de agricultura urbana tem sido reconhecida como uma estratégia.

Agricultura urbana, segundo Mougeot (2005), é usualmente classificada de acordo com os seguintes determinantes: tipos de atividade econômica; localização intraurbana ou periurbana; tipos de área onde é praticada; sua escala e sistema de produção; as categorias dos produtos (alimentícios e não alimentícios); e a destinação dos produtos. Inevitavelmente o fator mais comumente relacionado é o da localização, já que, na 


\section{SÃO PAULO15 $\sim 17 \cdot$ LISBOA $25 \sim 26$ JUN 2020

sua nomenclatura, o termo "urbana" acompanha e restringe onde a prática de agricultura é empregada (Mougeot, 2005).

De acordo com Lovo (2011), a história da agricultura urbana pode ser caracterizada a partir da Revolução Industrial, em que a produção de alimentos em espaços urbanos se viu intensificada por estar associada a crises econômicas. Relatos semelhantes podem ser observados em diferentes épocas, inclusive atualmente, em que a produção de alimento nas cidades se fundamenta em criar oportunidades em situações de crises socioeconômicas.

As experiências de agricultura urbana no cenário atual mostram que os seus benefícios são inúmeros. Esse ganho ultrapassa a dimensão ambiental e pode ser constatada, inclusive, nas esferas sociais e econômica (Ricarte-Covarrubias, 2011).

Segundo Barbieri e Viana (2013, p. 61), as práticas de agricultura urbana devem ser encaradas como medidas adaptativas às mudanças climáticas globais "já que podem atuar na redução da vulnerabilidade de determinadas populações e aumentar a resiliência e a capacidade de resposta de algumas cidades". Essa prática, proposta como uma infraestrutura verde, é tratada sob os aspectos da melhoria do microclima, do aumento da infiltração da água no solo, da captura de $\mathrm{CO} 2$ da atmosfera e ainda da produção de alimentos sem o uso - ou com o uso diminuído - de defensivos agrícolas.

\section{Vazios urbanos e a função social da propriedade urbana}

A virada do século XXI trouxe uma nova realidade urbana. Nessa ocasião, mais precisamente em 2007, o quantitativo de população mundial habitando as cidades superou o número de moradores do campo. No Brasil, essa condição deu-se décadas antes - entre os anos 1960 e 1970 (Leite, 2012). As estruturas urbanas, por consequência, alteraram-se com o processo de migração campo-cidade e sua configuração passou por diversas transformações econômicas, sociais, culturais e políticas. As cidades, por consequência, alteraramse com esse processo de migração campo-cidade e sua configuração passou por transformações econômicas, sociais, culturais e políticas (Hespanhol, 2013).

O crescimento urbano, com destaque para os países em desenvolvimento, como no caso do Brasil, tem como característica a convivência com a desigualdade na distribuição de renda e oportunidades econômicas, o que acaba gerando cidades díspares (Leite, 2012). Assim, constata-se um processo de urbanização brasileiro deuse de forma socialmente desigual. Tal fator pode ser percebido quanto ao acesso à terra urbana e à sua qualidade (Sposito, 2017).

No Brasil, a noção de função social da propriedade não é nova, fazendo-se presente na Constituição da República de 1934. O inciso 17 do artigo 113 desta Constituição apresenta que "É garantido o direito de propriedade, que não poderá ser exercido contra o interesse social ou coletivo, na forma que a lei determinar" (Brasil, 1934).

$\mathrm{Na}$ Constituição Federal de 1988 o conceito de função social da propriedade reaparece a fim de garantir o uso da mesma a partir da noção de bem coletivo. O direito à propriedade não é questionado, ele é mantido pelo artigo 5, inciso XXII. Mas, o inciso XXIII do mesmo artigo, indicará que "a propriedade atenderá a sua função social" (Brasil, 1988). Sendo expressas as condições para o seu atendimento, os artigos 182 e 184.

Para o caso urbano, o parágrafo segundo do artigo 182 indica que "A propriedade urbana cumpre sua função social quando atende às exigências fundamentais de ordenação da cidade expressas no plano diretor". O Plano Diretor é uma lei municipal cujo conteúdo mínimo foi estabelecido pela Lei no 10.257 de 10 de julho de 2001, 


\section{SÃO PAULO15 $\sim 17 \cdot$ LISBOA $25 \sim 26$ JUN 2020

denominada de Estatuto das Cidades. Essa lei "estabelece normas de ordem pública e interesse social que regulam o uso da propriedade urbana em prol do bem coletivo" (Brasil, 2001). A partir da qual se apresentam diretrizes nas quais se inclui a garantia do direito a cidades sustentáveis (Brasil, 2018).

Ao regular os elementos de ordenamento do espaço, o plano diretor deverá apresentar os parâmetros de parcelamento, a edificação ou a utilização compulsória do solo urbano não edificado, subutilizado ou não utilizado. Nesse caso, caberá a cada município estipular esse parâmetro, dentro dos quais, inserem-se os vazios urbanos.

As discussões sobre a função social da propriedade urbana perpassam o debate acerca do direito à cidade. Para quem deve ser as cidades? Para as pessoas? Para os negócios? Para os serviços? Como os espaços intraurbanos podem ser destinados para se garantir um uso e acesso equitativo? Mas, se a sociedade se apresenta caracterizada por amplos processos de desigualdade socioeconômica, como as cidades podem evitar um uso desigual dos seus espaços?

Lefebvre (2001), precursor no debate do direito à cidade, discute sobre as contradições existentes entre a realidade da sociedade e o meio em que ela se insere, buscando entender a contradição entre a "socialização da sociedade e a segregação generalizada" (Lefebvre, 2001: 116). O autor afirma que os direitos surgem dessas contradições somadas à pressão da classe operária. Esses direitos são: "direitos das idades e dos sexos, direitos das condições, direitos à instrução e educação, direito ao trabalho, à cultura, ao repouso, à saúde, à educação e, por último, o direito à natureza que entrou para a prática social em favor dos lazeres" (Lefebvre, 2001, p. 116-117). Porém, critica esse último em decorrência da comercialização e industrialização desses espaços que acabam por destruir a sua "naturalidade".

O direito à cidade, entendido como uma síntese dos direitos anteriormente citados, se mostra como uma forma superior dos direitos - "direito à liberdade, à individualização na socialização, ao habitat e ao habitar" (Lefebvre, 2001, p. 134) - e se afirma como um apelo, uma exigência.

Harvey (2014), em seu recente estudo intitulado Cidades Rebeldes, retoma o legado intelectual de Lefebvre e contrapõe a dialética do direito à cidade apresentado anteriormente com a insurgência dos movimentos sociais urbanos. Para o autor, os movimentos de luta pelo direito à cidade na atualidade (início século XXI) não estão relacionados com o legado de Lefebvre, mas sim com as lutas que configuram as características da vida urbana cotidiana. Harvey (2014, p. 15) conclui:

A ideia do direito à cidade não surge fundamentalmente de diferentes caprichos e modismos intelectuais (embora eles existam em grande número, como sabemos). Surge basicamente das ruas, dos bairros, como um grito de socorro e amparo de pessoas oprimidas em tempos de desespero.

Harvey (2014) pensa o direito à cidade numa perspectiva de inclusão social, ou seja, de uma cidade destinada a todos cujo morar tenha uma centralidade a partir da noção de necessidade (bem de uso) e não como um bem de troca. Para o autor, a cidade não deve ser tomada apenas como uma forma de investimento, arraigado pelo setor financeiro e imobiliário. Essa necessidade básica do morar (habitar) se expressa no perfil dos grupos sociais ligados à luta pelo direito à cidade, formados por:

Moradores de baixa renda em comunidades negras que lutam pelo tipo de desenvolvimento que vá de encontro a seus desejos e necessidades, pessoas semteto que se organizam por seu direito à moradia e aos serviços básicos e os jovens 



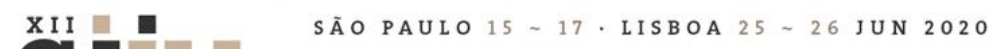

interstícios desse crescimento terrenos vagos, mantidos fora de mercado à espera da valorização imobiliária" (Cardoso, 2012: 19).

Cardoso (2012) afirma que esta forma de especulação ou valorização imobiliária sempre esteve relacionado ao modo de intervenção do Estado no parcelamento e ocupação do solo. O poder público instalava condições de infraestrutura e esses terrenos vazios, que já não mais se encontravam na periferia e sim em áreas mais centrais, acabavam por se valorizar indiscriminadamente. Cardoso (2012: 19) define esse processo como "disfuncional" e "perverso" a partir dos seguintes argumentos:

Porque mantinha "artificialmente" grandes extensões de terra fora do mercado, pressionando para cima o preço dos terrenos em oferta; porque implicava em um maior custo de investimento para a instalação das infraestruturas nas áreas efetivamente ocupadas; e porque o investimento público em infraestrutura resultava na valorização de áreas privadas.

O cumprimento da função social da propriedade delimitado pela Lei 10.257 (2001) traz em si alguns instrumentos urbanísticos como ferramentas para combater a especulação imobiliária, dentre elas: edificação e utilização compulsórios; IPTU (Imposto Predial e Territorial Urbano) progressivo com desapropriação e pagamentos em títulos da dívida pública; direito de preempção; outorga onerosa do direito de construir; transferência do direito de construir; e operação urbana consorciada.

\section{3. $O$ caso de Goiânia}

O município de Goiânia foi planejado e fundado em 24 de outubro de 1933 com a finalidade de ser a nova capital do estado de Goiás. Em 2018, Goiânia contava com 1,4 milhões de habitantes e densidade demográfica de 2.052,17 hab/km² (IBGE, 2018). A capital situa-se no planalto central brasileiro na região Centro-Oeste com latitude $16^{\circ} 40^{\prime} 43^{\prime \prime}$ Sul e longitude 49¹5'14" Oeste, e altitude média de 749 metros.

Goiânia encontra-se regida pelo Plano Diretor de 2007 (Lei n 171/2007) embora, em 2019, tenha sido enviado nova proposta de lei para a Câmara Municipal, que se encontrava em revisão desde 2017 pela municipalidade (Goiânia, 2007). 


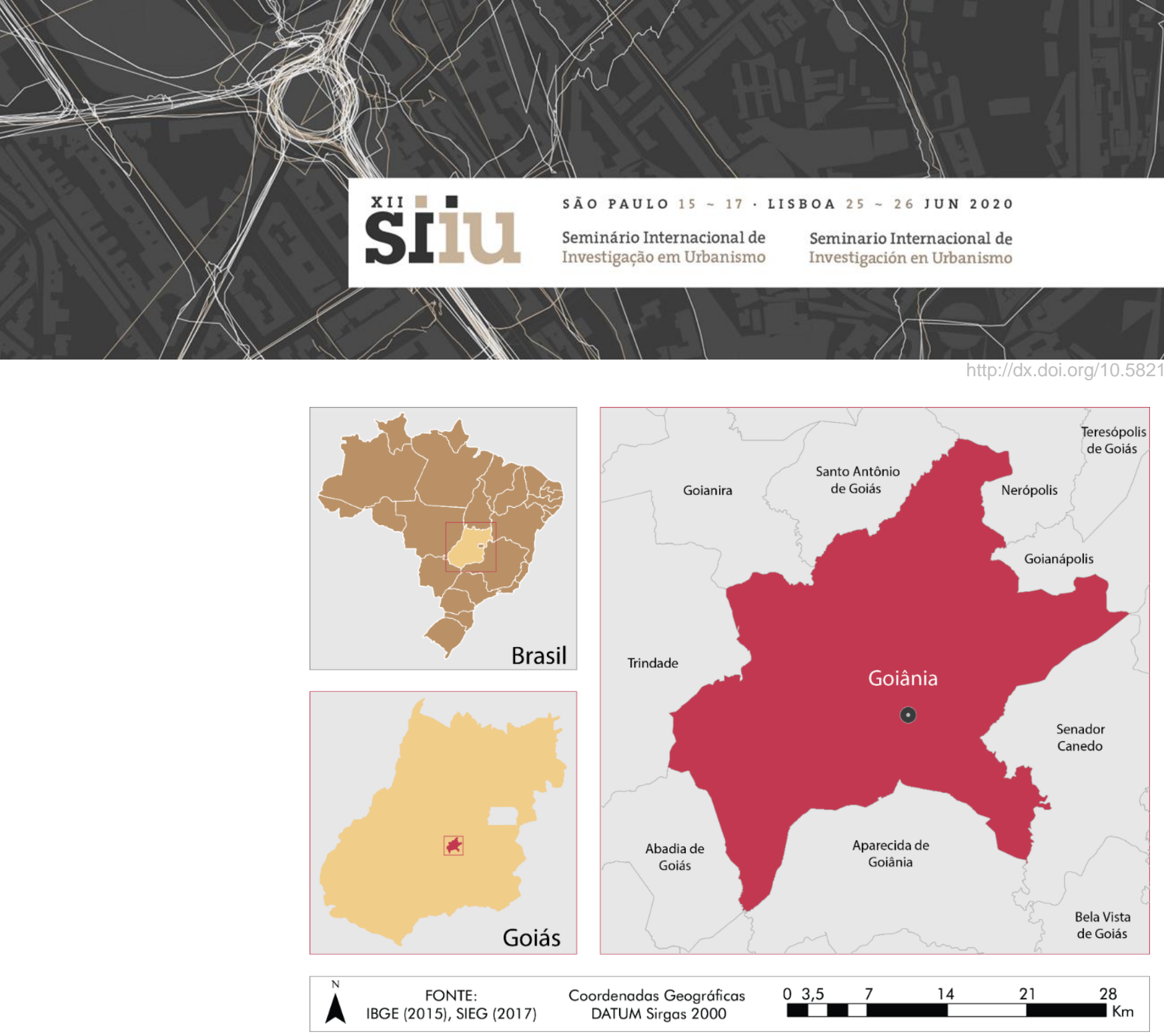

Fig. 01: Localização do município de Goiânia. Elaboração própria a partir de dados do IBGE (2015) e SIEG (2017).

Alguns estudos já abordam a prática de agricultura em Goiânia. O mais recente deles, realizado por Sousa (2019), levanta, quantifica e mapeia as práticas de agricultura no tecido urbano - subdividas nas regiões administrativas - e nos sítios periurbanos. Marçal et al (2019) apresentam a agricultura urbana como estratégia de ocupação dos vazios urbanos e de áreas ociosas e mapeiam áreas prioritárias dessa iniciativa afim de "promover a diversidade e inclusão social e cultural, cooperar com a prestação de serviços ambientais e contribuir com a melhoria da produtividade da cidade e com a segurança alimentar e nutricional de grupos vulneráveis" (Marçal et al, 2019: 5). Marçal et al (2019) ainda apontam a prática de agricultura urbana e periurbana em Goiânia como possível solução para mitigação e adaptação urbana num contexto de mudanças climáticas globais.

O Plano Diretor de 2007, no seu Artigo 40, prevê a implementação de programas estratégicos de desenvolvimento econômico e uma das diretrizes estabelece: "assegurar a promoção e a integração entre os municípios da Região Metropolitana de Goiânia, em função do desenvolvimento sustentável da ocupação territorial, da consolidação do cinturão verde, da produção agropecuária, da agroindústria, da agricultura familiar e outras atividades urbanas" (Goiânia, 2007). Porém, na prática, não se vê muito engajamento do poder público perante a essas práticas. Pouco se tem discutido a respeito de possíveis espaços para a implementação de agricultura urbana no município.

\section{Considerações finais}

Esta pesquisa buscou discutir as questões teóricas acerca da agricultura urbana como uma das estratégias de adaptação das mudanças climáticas globais. Para tornar o debate mais palpável, o estudo trouxe ainda a 


\section{SÃOPAULO15 $17 \cdot$ LISBOA $25 \sim 26$ JUN 2020}

espacialização dos vazios urbanos como locais propícios para a prática de agricultura urbana e procurou ainda trazer como pano de fundo o caso de Goiânia.

No contexto do debate das estratégias de enfrentamento das cidades perante às mudanças climáticas globais a agricultura urbana se apresenta, de fato, como uma atividade de adaptação para tornar as cidades resilientes. Com a necessidade de se especializar essa atividade, os vazios urbanos se mostram, efetivamente, locais passíveis de ocupação numa perspectiva que vai para além do adensamento, propondo práticas ambientais e assegurando a justiça social no que diz respeito ao cumprimento da função social da propriedade urbana.

\section{REFERÊNCIAS}

BARBIERI, A. F.; VIANA, R. M. (2013). Respostas urbanas às mudanças climáticas: construção de políticas públicas e capacidades de planejamento. In: OJIMA, R.; MARANDOLA JR, E. Mudanças climáticas e as cidades: novos e antigos debates na busca da sustentabilidade urbana e social (57-73). São Paulo: Blucher.

Brasil. Constituição da República dos Estados Unidos do Brasil (1934).

Brasil. Constituição da República Federativa do Brasil (1988).

Brasil. Lei no 10.257 (2001). Estatuto da Cidade. Regulamenta os arts. 182 e 183 da Constituição Federal, estabelece diretrizes gerais da política urbana e dá outras providências.

BRASIL. Ministério do Planejamento, Desenvolvimento e Gestão (2018). Contribuições à nova agenda urbana: o relatório do concidades para a conferência HABITAT III.

BUENO, L. M. M. (2013). A adaptação da cidade às mudanças climáticas: uma agenda de pesquisa e uma agenda política. In: OJIMA, R.; MARANDOLA JR, E. Mudanças climáticas e as cidades: novos e antigos debates na busca da sustentabilidade urbana e social (23-56). São Paulo: Blucher.

CARDOSO, A. L (2012). Vazios urbanos e função social da propriedade. In: FERREIRA, R. F. C. F.; BIASOTTO, R. C. Políticas públicas e direito à cidade: política habitacional e o direito à moradia digna. Programa interdisciplinar de formação de agentes sociais e conselheiros municipais (17-26). Rio de Janeiro: Letra Capital.

CORRÊA, R. L. (2011). Sobre agentes sociais, escala e produção do espaço: um texto para discussão. In: CARLOS, A. F. A.; SOUZA, M. L.; SPOSITO, M. E. B. Produção do espaço urbano: agentes e processos, escalas e desafios (41-52). São Paulo: Contexto.

DELGADO, C (2017). Agricultura urbana, alterações climáticas e cidades: um triângulo latente em que urge trabalhar. Revista Quercus (Lisboa), 80, 6-7.

GIDDENS, A. (2010). A política da mudança climática. Rio de Janeiro: Zahar.

Goiânia. Lei complementar no 171 (2007). Dispõe sobre o Plano Diretor e o processo de planejamento urbano no Município de Goiânia e dá outras providências.

Goiânia. Lei complementar no 181 (2008). Dispõe sobre Solo Urbano não edificado, subutilizado ou não utilizado em regulamentação ao art. 135 da Lei 171/2007 - Plano Diretor, altera as Leis Complementares n. 5.040/75 - Código Tributário Municipal, 171/2007 - Plano Diretor de Goiânia, e, 177/2008 - Código de Obras e dá outras providências. 


\section{S ĨO PAULO15 17 LISBOA $25 \sim 26$ JUN 2020}

HABITAT III (2016). A nova agenda urbana. Organização das Ações Unidas.

HARVEY, D. (1980). A justiça social e a cidade. São Paulo: Hucitec.

HARVEY, D. (1992). Condição pós-moderna. São Paulo: Edições Loyola.

HARVEY, D (2014). Cidades rebeldes: do direito à cidade à revolução urbana. São Paulo: Martins Fontes.

HESPANHOL, R. A. M. (2013). CAMPO E CIDADE, RURAL E URBANO NO BRASIL CONTEMPORÂNEO. Revista Mercator (Fortaleza), 12, 103-112.

LEFEBVRE, H (2001). O direito à cidade. São Paulo: Centauro.

LEITE, C. (2012). Cidades sustentáveis, cidades inteligentes: desenvolvimento sustentável num planeta urbano. Porto Alegre: Bookman.

LOVO, I. C. (2011). Agricultura urbana: um elo entre o ambiente e a cidadania. Tese de Doutorado. Universidade Federal de Santa Catarina (Florianópolis).

MARÇAL, D. R.; MESQUITA, G. G. M.; KALLAS, L. M. E.; HORA, K. E. R. (2019). Urban and peri-urban agriculture in Goiânia: searching for solutions for mitigation and urban adaptation in a context of global climate change. 5th International Conference on Countermeasures to Urban Heat Islands, Índia.

MARICATO, E. (2013). Brasil, cidades: alternativas para a crise urbana. Rio de Janeiro: Vozes.

MARICATO, E. (2015). Para entender a crise urbana. São Paulo: Expressão Popular.

MARTINS, R. D.; FERREIRA, L. C. (2011). Uma revisão crítica sobre cidades e mudança climática: vinho velho em garrafa nova ou um novo paradigma de ação para governança local? Revista de Administração Pública (Rio de Janeiro), 45, 611-641.

MONTE-MÓR, R. L. (2006). O que é urbano no mundo contemporâneo. Revista Paranaense de Desenvolvimento (Curitiba), 11, 9-18.

MOTA, S. (2003). Urbanização e meio ambiente. Rio de Janeiro: ABES.

MOUGEOT, L. J. A (2005). Agricultura urbana: conceito e definição. Revista de Agricultura Urbana, 1, 1-8.

MOURA, J. A.; FERREIRA, W. R.; LARA, L. B. L. S. (2013). AGRICULTURA URBANA E PERIURBANA. Revista de Geografia da UFC (Fortaleza), 27, 69-80.

OJIMA, R. (2013). Entre vulnerabilidades e adaptações: notas metodológicas sobre o estudo das cidades e as mudanças climáticas. In: OJIMA, R; MARANDOLA JR, E. (235-263). Mudanças climáticas e as cidades: novos e antigos debates na busca da sustentabilidade urbana e social. São Paulo: Blucher.

RIBEIRO, L. C. Q.; SANTOS JUNIOR, O. A. S. (2012). Desafios da questão urbana na perspectiva do direito à cidade. In: FERREIRA, R. F. C. F.; BIASOTTO, R. C. Políticas públicas e direito à cidade: política habitacional e 0 direito à moradia digna (9-16). Rio de Janeiro: Letra Capital.

RICATE-COVARRUBIAS, J. D. (2011). AGRICULTURA URBANA EM PORTO FERREIRA/SP: MAPEAMENTO, CARACTERIZAÇÃO E TIPIFICAÇÃO. Dissertação de Mestrado. Universidade Federal de São Carlos (Araras).

SILVA, G. F. N.; HORA, K. E. R. (2013). O PLANO DIRETOR MUNICIPAL E SUA INTERFACE COM A DRENAGEM URBANA. Revista LABVERDE, 7, 142-167. 


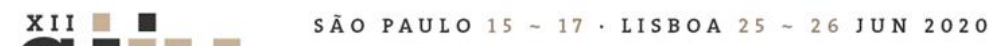

SOUSA, R. P. O. (2019). Agricultura urbana em Goiânia (GO)?. Dissertação de Mestrado. Universidade Federal de Goiás (Goiânia).

SPERANDIO, A. M. G.; MATTOS, T. P.; FRANCISCO FILHO, L. L.; FÁVERO, E.; DIAS, A.; RIBEIRO, M. M.; MANFRINATO, T. (2015). Ocupação de vazio urbano como promotor do planejamento para cidade sustentável. Revista PARC (Campinas), 3, 205-215.

SPOSITO, M. E. B. (2003). O embate entre as questões ambientais e sociais no urbano. In: CARLOS, A. F. A.; LEMOS, A. I. G. Dilemas urbanos: novas abordagens sobre a cidade (295-297). São Paulo: Contexto.

SPOSITO, M. E. B (2017). Capitalismo e urbanização. São Paulo: Contexto.

VIDEIRO ROSA, P. P (2011). POLÍTICAS PÚBLICAS EM AGRICULTURA URBANA E PERIURBANA NO BRASIL. Revista Geográfica de América Central (Heredia), 2, 1-17.

Fontes eletrônicas

https://cidades.ibge.gov.br/brasil/go/goiania/panorama. Consulta: 17/10/2019. (IBGE, Goiânia, 2018). 